\title{
Pulse radiolysis studies of functionally substituted imidazolium-based ionic liquids
}

\author{
FU HaiYing ${ }^{*}$, XING ZhaoGuo $^{1,2}$, CAO XiYan ${ }^{2} \&$ WU GuoZhong ${ }^{1}$ \\ ${ }^{1}$ Shanghai Institute of Applied Physics, Chinese Academy of Sciences, Shanghai 201800, China; \\ ${ }^{2}$ Hunan University of Science and Technology, Changsha 411201, China
}

Received November 6, 2011; accepted February 2, 2012; published online May 19, 2012

\begin{abstract}
The reactions of imidazolium-based ionic liquids having different substituent groups on the ring with hydrated electrons ( $\mathrm{e}_{\mathrm{aq}}^{-}$), hydroxyl radicals $\left({ }^{\circ} \mathrm{OH}\right)$, and sulfate anion radicals $\left(\mathrm{SO}_{4}{ }^{--}\right)$were investigated using nanosecond pulse radiolysis techniques. The spectra of these ionic liquids on reaction with $\mathrm{e}_{\mathrm{aq}}{ }^{-}$all exhibited a similar peak at about $320 \mathrm{~nm}$, and a typical peak for $\mathrm{e}_{\mathrm{aq}}^{-}$in aqueous ionic liquid solutions. The reaction rate constants for 1,3-disubstituted imidazolium-based ionic liquid hexafluorophosphates $\left(\mathrm{BMIPF}_{6}\right)$ with $\mathrm{e}_{\mathrm{aq}}{ }^{-}$were deduced to be $10^{10} \mathrm{~L} \mathrm{~mol}^{-1} \mathrm{~s}^{-1}$, however the values were lower for trisubstituted ionic liquids. For example, the rate constant for 1-butyl-2,3-dimethylimidazolium tetrafluoroborate $\left(\mathrm{BMMIBF}_{4}\right)$ was $5.5 \times 10^{9} \mathrm{~L} \mathrm{~mol}^{-1} \mathrm{~s}^{-1}$. Imidazolium-based ionic liquids reacted with hydroxyl radicals via adducts to produce a mixture of isomeric $\mathrm{OH}$ adducts, and the $\mathrm{p} k_{\mathrm{a}}$ value of the $\mathrm{OH}$ adducts was deduced to be $8.4 \pm 0.4$ for 1-butyl-3-methylimdazolium tetrafluoroborate $\left(\mathrm{BMIBF}_{4}\right)$. Moreover, imidazolium cations were also oxidized by $\mathrm{SO}_{4}{ }^{--}$to produce bivalent cation radicals, which exhibit a peak at $320 \mathrm{~nm}$, and these rate constants are of the same order of magnitude, i.e., $10^{9} \mathrm{~L} \mathrm{~mol}^{-1} \mathrm{~s}^{-1}$, except that for 1-(2-hydroxyethyl)-3-methylimdazolium tetrafluoroborate with $\mathrm{SO}_{4}^{--}\left(k=2.8 \times 10^{8} \mathrm{~L} \mathrm{~mol}^{-1} \mathrm{~s}^{-1}\right)$. Theoretical calculations were carried out to estimate the structures of the products of reduction by $\mathrm{e}_{\mathrm{aq}}{ }^{-}$and the results were related to the experimental data.
\end{abstract}

pulse radiolysis, imidazolium-based ionic liquids, kinetics, rate constants

Citation: Fu H Y, Xing Z G, Cao X Y, et al. Pulse radiolysis studies of functionally substituted imidazolium-based ionic liquids. Chin Sci Bull, 2012, 57: 2752-2758, doi: 10.1007/s11434-012-5129-8

Room-temperature ionic liquids (RTILs), which have low melting points $\left(T_{\mathrm{m}}\right.$ typically $\left.<100^{\circ} \mathrm{C}\right)$, are usually liquids composed of bulky organic cations and smaller inorganic anions. RTILs have been receiving increasing attention in recent years because of their low volatility, high polarity, ease of recycling, and high thermal stability compared to those of common solvents [1-3]. They have therefore been proposed as "green solvents" for chemical reactions and separation processes [4-6]. One important application of RTILs is as media for the processing of spent nuclear fuels $[6,7]$. It is therefore necessary to observe the characteristics of radiation chemistry in ionic liquids to understand the factors that control their stability under ionizing radiation, and to study the kinetics using pulse radiolysis methods

*Corresponding author (email: fuhaiying@ sinap.ac.cn)
[8-11]. The direct observation of solvated electrons in an ionic liquid was first reported for methyltributylammonium bis(trifluoromethylsulfonyl)imide; $\mathrm{e}_{\text {solv }}^{-}$has a lifetime of $\sim 300 \mathrm{~ns}$ and a broad absorption spectrum that peaks at 1400 $\mathrm{nm}$ [12]. To compare the rate constants in ionic liquids with those in other solvents, Neta and co-workers [9,10,13] investigated the reactions of $\mathrm{CCl}_{3} \mathrm{O}_{2}{ }^{\bullet}$ radicals with Trolox and chlorpromazine, which have been studied in a wide variety of solvents. However, there have been few reported radiolysis studies of functionalized ionic liquids, although many "task-specific" liquids have been designed to control solubility or to provide a specific prosthetic group such as a reagent or catalyst. Wishart et al. [14] studied the effects of functional group substitution on the spectra of solvated electrons in different types of quaternary ammonium ionic liquids. The energetics and mobilities of intermediate electron solva- 
tion states were observed for several hundred nanoseconds, and the blue shift took place in a very short time (25-40 ns).

The structures of the cations and anions are shown in Scheme 1. In the present study, the transient processes of imidazolium-based ionic liquids with various substituent groups on the imidazole ring with radicals such as ${ }^{\circ} \mathrm{OH}, \mathrm{e}_{\mathrm{aq}}^{-}$, and $\mathrm{SO}_{4}{ }^{--}$were observed using nanosecond pulse radiolysis techniques. The kinetics were determined, and the influences of various functional groups on the imidazolium ring and different anions on the kinetics are also discussed.

\section{Experimental}

\subsection{Materials}

All ionic liquids were provided by the Chengjie Chemical Company (Shanghai, China), and were of the highest purity available commercially. Prior to use, the ionic liquids were treated with activated charcoal for at least $48 \mathrm{~h}$ and filtered twice by passing through a Celite column. The liquids were then transferred to a clean dry reagent bottle and kept under vacuum for $12 \mathrm{~h}$ at $65^{\circ} \mathrm{C}$ to remove any volatile organic
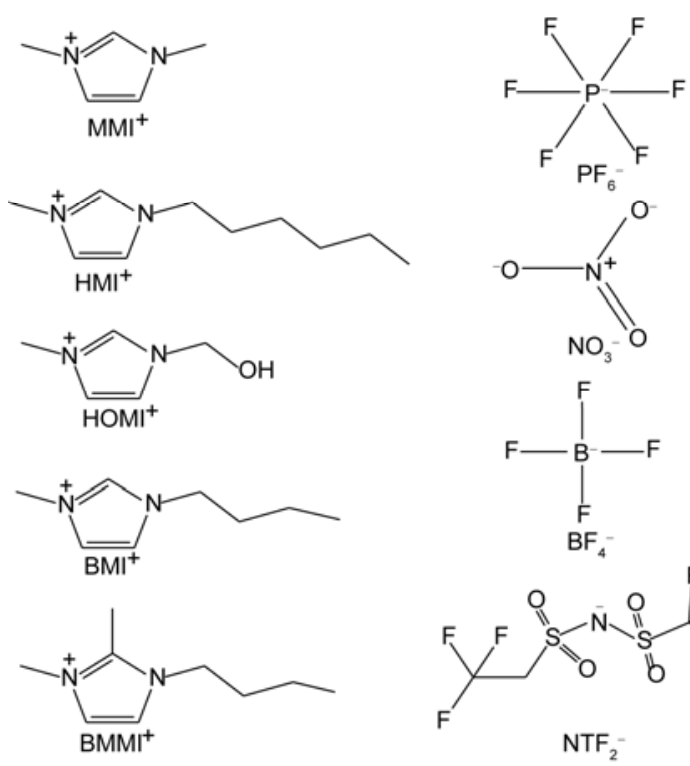<smiles>[B-][B-](F)(F)F</smiles>

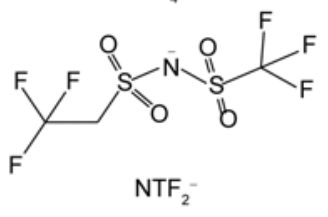

Scheme 1 Structures of imidazolium-based ionic liquids. impurities and moisture. The purified ionic liquids were stored in an airproof desiccator. Tert-butyl alcohols and $\mathrm{K}_{2} \mathrm{~S}_{2} \mathrm{O}_{8}$ were purchased from Sigma Company (Shanghai, China).

All sample solutions were freshly prepared in triply distilled water and deaerated with high purity $\mathrm{N}_{2}(99.99 \%)$ or $\mathrm{N}_{2} \mathrm{O}$, for different purposes, by bubbling for at least $20 \mathrm{~min}$ immediately before the experiments. All experiments were carried out at room temperature.

The ionic liquids used and their abbreviations are listed in Table 1. The imidazolium-based ionic liquids containing the anions $\mathrm{BF}_{4}{ }^{-}$or $\mathrm{NO}_{3}{ }^{-}$are soluble in water, whereas those with $\mathrm{NTF}_{2}^{-}$and $\mathrm{PF}_{6}{ }^{-}$are less soluble. At $20^{\circ} \mathrm{C}$, the solubility of $\mathrm{BMINTF}_{2}$ in water is about $1.4 \%$ and that of $\mathrm{BMIPF}_{6}$ is $2 \%$ [15].

\subsection{Pulse radiolysis}

Pulse radiolysis experiments were performed using a 10 meV linear accelerator delivering an electron pulse with a duration of $20 \mathrm{~ns}$, at the Shanghai Institute of Applied Physics. The electron pulse dosimetry was determined using a thiocyanate dosimeter with $G\left[(\mathrm{CNS})_{2}{ }^{\bullet-}\right]=6.0$ in a 100 mmol L ${ }^{-1}$ KSCN solution saturated with $\mathrm{N}_{2} \mathrm{O}$ by taking $\varepsilon_{480 \mathrm{~nm}}=7600 \mathrm{~L} \mathrm{~mol}^{-1} \mathrm{~cm}^{-1}$ for $(\mathrm{CNS})_{2}{ }^{\bullet-}$. $G$ value is known as radiation chemical yield, which means the number of molecules produced or destroyed for each 100 electronvolts absorbed by a substance from ionizing radiation. The details of the setup and operating conditions have been described elsewhere [16]. The dose was about 18 Gy per pulse. The uncertainties in the measurements of wavelength, transient absorption, and least-squares fitting in obtaining the rate constants were $\sim 1 \mathrm{~nm},<1$, and $<5 \%$, respectively.

\subsection{Reactions with radicals}

Free radicals were generated using standard methods for converting the primary species of the radiolysis of water, such as $\mathrm{e}_{\mathrm{aq}}^{-},{ }^{\bullet} \mathrm{OH}$, and ${ }^{\circ} \mathrm{H}$ (eq. (1)). To study only the reactions of hydroxyl radicals, solutions were pre-saturated with $\mathrm{N}_{2} \mathrm{O}$, which quantitatively converts hydrated electrons to hydroxyl radicals via eq. (2) [17].

Table 1 Full and abbreviated names of ionic liquids used in the experiments

\begin{tabular}{ll}
\hline Abbreviated names & \multicolumn{1}{c}{ Full names } \\
\hline $\mathrm{MMIBF}_{4}$ & 1,3-Dimethylimdazolium tetrafluoroborate \\
$\mathrm{BMIBF}_{4}$ & 1-Butyl-3-methylimdazolium tetrafluoroborate \\
$\mathrm{HMIBF}_{4}$ & 1-Hexyl-3-methylimdazolium tetrafluoroborate \\
$\mathrm{BMMIBF}_{4}$ & 1-Butyl-2,3-dimethylimdazolium tetrafluoroborate \\
$\mathrm{HOMIBF}_{4}$ & 1-(2'-Hydroxylethyl)-3-methylimdazolium tetrafluoroborate \\
$\mathrm{BMIPF}_{6}$ & 1-Butyl-3-methylimdazolium hexafluorophosphate \\
$\mathrm{BMINO}_{2}$ & 1-Butyl-3-methylimdazolium bis(trifluoromethylsulfonyl)imide \\
\hline
\end{tabular}




$$
\begin{gathered}
\mathrm{H}_{2} \mathrm{O} \longrightarrow \mathrm{e}_{\mathrm{aq}}^{-},{ }^{\circ} \mathrm{OH},{ }^{\bullet} \mathrm{H}, \mathrm{H}_{3} \mathrm{O}^{+}, \mathrm{H}_{2} \mathrm{O}_{2}, \mathrm{HO}_{2}, \ldots \\
\mathrm{e}_{\mathrm{aq}}^{-}+\mathrm{N}_{2} \mathrm{O} \longrightarrow{ }^{\bullet} \mathrm{OH}+\mathrm{OH}^{-}+\mathrm{N}_{2}
\end{gathered}
$$

To achieve reactions of hydrated electrons, the solutions were pre-saturated with $\mathrm{N}_{2}$ in the presence of $1.0 \mathrm{~mol} \mathrm{~L}^{-1}$ tert-butyl alcohol $(t-\mathrm{BuOH})$, which can be converted into the relatively inert $t$ - $\mathrm{BuOH}$ radicals by scavenging hydroxyl radicals and hydrogen radicals (see eqs. (3) and (4)) [17].

$$
\begin{gathered}
\cdot \mathrm{OH}+\left(\mathrm{CH}_{3}\right)_{3} \mathrm{COH} \longrightarrow \mathrm{H}_{2} \mathrm{O}+{ }^{\circ} \mathrm{CH}_{2}\left(\mathrm{CH}_{3}\right)_{2} \mathrm{COH} \\
\mathrm{H}^{\bullet}+\left(\mathrm{CH}_{3}\right)_{3} \mathrm{COH} \longrightarrow{ }^{\circ} \mathrm{CH}_{2}\left(\mathrm{CH}_{3}\right)_{2} \mathrm{COH}+\mathrm{H}_{2}
\end{gathered}
$$

In the system, ${ }^{\circ} \mathrm{H}$ and $\mathrm{e}_{\mathrm{aq}}{ }^{-}$react with $\mathrm{S}_{2} \mathrm{O}_{8}{ }^{2-}$ to produce $\mathrm{SO}_{4}{ }^{--}$(eqs. (5) and (6)).

$$
\begin{aligned}
& \mathrm{e}_{\mathrm{aq}}^{-}+\mathrm{S}_{2} \mathrm{O}_{8}{ }^{2-} \longrightarrow \mathrm{SO}_{4}{ }^{--}+\mathrm{SO}_{4}{ }^{2-} \\
& { }^{\circ} \mathrm{H}+\mathrm{S}_{2} \mathrm{O}_{8}{ }^{2-} \longrightarrow \mathrm{SO}_{4}{ }^{--}+\mathrm{HSO}_{4}{ }^{-}
\end{aligned}
$$

\section{Results and discussion}

\subsection{Reactions with hydrated electrons}

The transient absorption spectrum was obtained under pulse radiolysis for an aqueous solution containing $\mathrm{BMIBF}_{4}(0.1$ mmol L $\left.{ }^{-1}\right)$ and $t$-BuOH $\left(1.0 \mathrm{~mol} \mathrm{~L}^{-1}\right)$, deoxygenated with $\mathrm{N}_{2}$ (Figure 1). A strong absorption spectrum appears over a broad region from 470 to $740 \mathrm{~nm}$ in a very short lifetime. This absorption spectrum had a maximum absorption at around $700 \mathrm{~nm}$ and was assigned to that of hydrated electrons, by comparison with previous studies [17]. As shown in Figure 1 and insert (a), after the decay of a hydrated electron, a new transient species with a characteristic absorption band at around $320 \mathrm{~nm}$ was observed; this was attributed to addition of an electron to give the neutral $\mathrm{BMI}^{\bullet}$ radical.

$$
\mathrm{e}_{\mathrm{aq}}^{-}+\mathrm{BMI}^{+} \longrightarrow \mathrm{BMI}^{\circ}
$$

It is known that $\mathrm{e}_{\mathrm{aq}}^{-}$does not react with $\mathrm{Cl}^{-}$, and it can be assumed that $\mathrm{e}_{\mathrm{aq}}^{-}$does not react with $\mathrm{PF}_{6}^{-}, \mathrm{BF}_{4}^{-}$, or other anions. The rate of $\mathrm{e}_{\mathrm{aq}}^{-}$decay was unchanged in other ionic liquids. The rate constants were obtained by varying the $\mathrm{BMIBF}_{4}$ concentration (Figure 1, inset (b)). The values of the rate constants for $\mathrm{e}_{\mathrm{aq}}^{-}$with imidazolium ionic liquids are summarized in Table 2. The values were consistent with the results obtained using 1-methylimdazolium ions [18] and 1-butyl-3-methylimidazolium chloride [13].

When the 2-position of the imidazole ring was alkylated, the rate constant was smaller than that for an imidazole with no alkyl group at position 2. The reaction constants of three C2-alkyl imidazolium cations [1-ethyl-2,3-dimethylimdazolium, 1-butyl-2,3-dimethylimdazolium $\left(\mathrm{BMMI}^{+}\right)$, 1-hexyl2,3-dimethylimdazolium] with hydrated electrons were examined, and were found to be very close each other, $5.9 \times 10^{9}, 5.5 \times 10^{9}$, and $5.1 \times 10^{9} \mathrm{~L} \mathrm{~mol}^{-1} \mathrm{~s}^{-1}$, respectively, whereas that of the $\mathrm{BMI}^{+}$cation was $1.8 \times 10^{10} \mathrm{~L} \mathrm{~mol}^{-1} \mathrm{~s}^{-1}$. These findings are quite similar to those of Takahashi et al. [19]. They found that alkylation of the imidazolium suppresses reactivity with dry electrons. The influence may be less in aqueous solutions than in neat ionic liquids as a

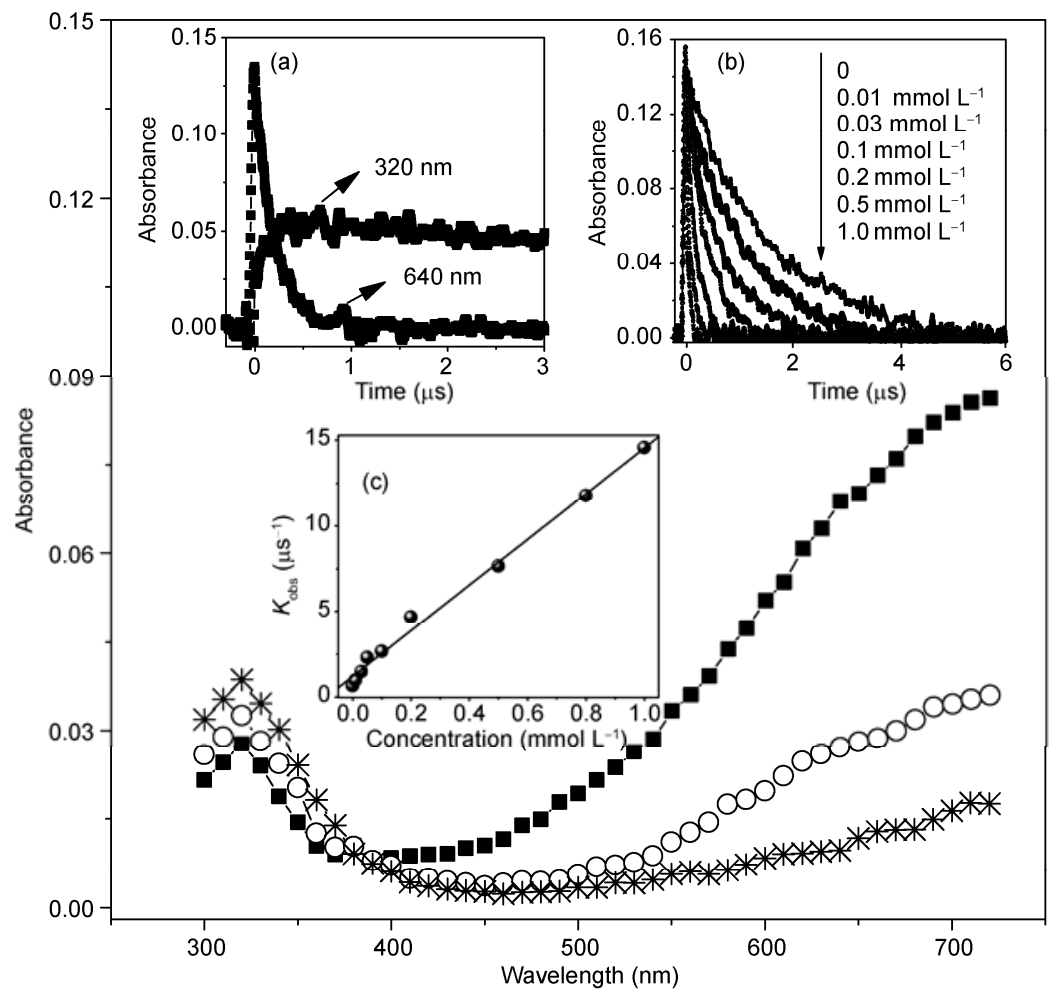

Figure 1 Transient absorption spectra of the radicals produced by radiolysis of $0.1 \mathrm{mmol} \mathrm{L}^{-1} \mathrm{BMIBF} 4$ in $\mathrm{N}_{2}$-saturated aqueous solutions at pH 7.1, buffered with $2 \mathrm{mmol} \mathrm{L}{ }^{-1}$ phosphate, recorded at (-) 0.1 , (०) 0.3 , and (*) $0.5 \mu$ s after the electron pulse. Insets: (a) Growth at $320 \mathrm{~nm}$ and decay at 640 nm; (b) time profiles observed at $640 \mathrm{~nm}$ for $\mathrm{e}_{\mathrm{aq}}{ }^{-}$; and (c) decay rate of $\mathrm{e}_{\mathrm{aq}}{ }^{-}$at $640 \mathrm{~nm}$ plotted as a function of $\mathrm{BMINTF}_{2} \mathrm{concentration}$ 
Table 2 Rate constants for the reactions of ionic liquids with radicals

\begin{tabular}{lccc}
\hline \multirow{2}{*}{ RTILs } & \multicolumn{3}{c}{$k\left(\mathrm{~L} \mathrm{~mol}^{-1} \mathrm{~s}^{-1}\right)$} \\
\cline { 2 - 4 } & \multicolumn{1}{c}{$\mathrm{e}_{\mathrm{aq}}^{-}$} & $\mathrm{OH}$ & $\mathrm{SO}_{4}^{{ }^{-}}$ \\
\hline $\mathrm{MMIBF}_{4}$ & $2.5 \times 10^{10}$ & $4.2 \times 10^{9}$ & $1.0 \times 10^{9}$ \\
$\mathrm{BMIBF}_{4}$ & $1.8 \times 10^{10}$ & $3.3 \times 10^{9}$ & $1.2 \times 10^{9}$ \\
$\mathrm{HMIBF}_{4}$ & $1.3 \times 10^{10}$ & $3.1 \times 10^{9}$ & $2.5 \times 10^{9}$ \\
$\mathrm{BMMIBF}_{4}$ & $5.5 \times 10^{9}$ & $1.2 \times 10^{9}$ & $2.1 \times 10^{9}$ \\
$\mathrm{HOMIBF}_{4}$ & $1.7 \times 10^{10}$ & $2.6 \times 10^{9}$ & $2.8 \times 10^{8}$ \\
$\mathrm{BMINO}_{3}$ & $1.8 \times 10^{10}$ & $2.9 \times 10^{9}$ & $1.1 \times 10^{9}$ \\
$\mathrm{BMINTF}_{2}$ & $1.7 \times 10^{10}$ & $2.8 \times 10^{9}$ & $1.3 \times 10^{9}$ \\
$\mathrm{BMIPF}_{6}$ & $2.1 \times 10^{10}$ & $3.1 \times 10^{9}$ & $1.4 \times 10^{9}$ \\
\hline
\end{tabular}

result of the high viscosities of ionic liquids. In addition Hayashi et al. [20] reported that C2-alkylation of imidazolium cations is extremely effective in extending the electrochemical redox window of imidazolium-based ionic liquids.

To determine why $\mathrm{C} 2$-alkylation of imidazolium cations suppresses reactivity with radicals, we carried out $a b$ initio molecular orbital calculations on imidazolium-based cations and neutral radicals, namely 1,3-dimethylimdazolium,1butyl-2,3-dimethylimdazolium, 1-hexyl-3-methylimdazolium, 1-butyl-3-methylimdazolium, and 1-(2-hydroxyethyl)-3-methylimdazolium radicals, using the Gaussian 03 suite of programs [21]. All geometry optimizations were at the level of Becke's three-parameter hybrid exchange functional, and the density functional theory gradient-corrected correlation functional developed by Lee, Yang, and Parr (B3LYP) [22], and the $6-31 \mathrm{G}+(\mathrm{d}, \mathrm{p})$ basis set were used. It was found that all spin densities lie mainly at $\mathrm{C} 2$ of the imidazole ring for both cations and radicals (Tables 3 and 4). The results agree with those in the corresponding report by Behar et al. [13]. The structure of the electron adducts $\left(\mathrm{BMI}^{\circ}\right)$ is more closely represented by an allylic structure formed by the two nitrogens and $\mathrm{C} 2$, and which is not conjugated with the $\mathrm{C} 4=\mathrm{C} 5$ double bond, rather than by a fully conjugated structure. When there is C2-alkylation of the imidazolium cations, the $\mathrm{BMMI}^{+}$structures, which are more sterically hindered than those of $\mathrm{BMI}^{+}$, make it more difficult for $\mathrm{e}_{\mathrm{aq}}{ }^{-}$to attack position 2 of the imidazole ring. Furthermore, $\mathrm{CH}_{3}{ }^{-}$, as an electron-donating group, can increase the electron cloud at $\mathrm{C} 2$, which may be worse for the reaction of $\mathrm{e}_{\mathrm{aq}}{ }^{-}$with $\mathrm{BMMI}^{+}$ than for that with $\mathrm{BMI}^{+}$.

\subsection{Reactions with ${ }^{\bullet} \mathrm{OH}$}

An aqueous $\mathrm{N}_{2} \mathrm{O}$-saturated solution of $0.1 \mathrm{mmol} \mathrm{\textrm {L } ^ { - 1 }}$ $\mathrm{BMIBF}_{4}$ at $\mathrm{pH} 7.1$ was pulse-irradiated. The transient spectra showed a strong narrow absorption band at around 320 $\mathrm{nm}$, and another quite broad absorption band in the 390-460 $\mathrm{nm}$ range (Figure 2). These absorption bands were similar to those previously observed for $\mathrm{OH}$ adducts of imidazoles, as shown in eq. (8) $[13,18]$. The rate constant was determined for the rate of absorption buildup at $320 \mathrm{~nm}$, and was found to be $3.5 \times 10^{9} \mathrm{~L} \mathrm{~mol}^{-1} \mathrm{~s}^{-1}$ at $\mathrm{pH} 7.1$ (Figure 2, inset), only slightly lower than the value reported for the $N$ methylimidazolium cation $\left(5 \times 10^{9} \mathrm{~L} \mathrm{~mol}^{-1} \mathrm{~s}^{-1}\right)$ [18].

$$
\mathrm{BMI}^{+}+{ }^{\bullet} \mathrm{OH} \longrightarrow \mathrm{HO}-\mathrm{BMI}^{\bullet+}
$$

On varying the $\mathrm{pH}$ values from 5.5 to 11 , the rate constants of $\mathrm{BMIBF}_{4}$ reacting with $\mathrm{OH}$ radicals decreased from $3.5 \times 10^{9}$ to $0.9 \times 10^{9} \mathrm{~L} \mathrm{~mol}^{-1} \mathrm{~s}^{-1}$. This change indicated the existence of an acid-base equilibrium. Figure 3 shows the dependence of rate constants on $\mathrm{pH}$ values. Sigmoidal fitting of the origin showed that the $\mathrm{p} K_{\mathrm{a}}$ value of the $\mathrm{OH}$ adducts was $8.4 \pm 0.4$. The $\mathrm{OH}$ adducts therefore possibly undergo ionization followed by rearrangement, as shown in eq. (9).

$$
\mathrm{HO}-\mathrm{BMI}^{\bullet+}+\mathrm{OH}^{-} \rightleftharpoons{ }^{-} \mathrm{O}-\mathrm{BMI}+\mathrm{H}_{2} \mathrm{O}
$$

Table 3 Spin densities at the atomic centers of the imidazolium ring computed at the B3LYP/6-31+G (d,p) level of theory

\begin{tabular}{cccccc}
\hline Atom center & MMI $^{\bullet}$ & BMI $^{\bullet}$ & HMI $^{\bullet}$ & BMMI $^{\bullet}$ \\
N1 & 0.083958 & 0.109141 & 0.084024 & 0.021877 \\
C2 & 0.739019 & 0.797163 & 0.768075 & 1.078353 \\
N3 & 0.083932 & 0.037844 & 0.095249 & 0.115888 \\
C4 & 0.023402 & -0.012617 & 0.060588 & 0.735911 \\
C5 & 0.023640 & 0.074464 & 0.051850 & 0.096584 & -0.009596 \\
\hline
\end{tabular}

Table 4 Spin densities at the atomic centers on the imidazolium cation computed at the B3LYP/6-31+G (d, p) level of theory ${ }^{1)}$

\begin{tabular}{crrrrr}
\hline Atom center & MMI $^{+}$ & BMI $^{+}$ & HMI $^{+}$ & BMMI $^{+}$ & -0.1633 \\
N1 & -0.14896 & -0.151186 & -0.129232 & -0.22799 & -0.002439 \\
C2 & 0.00285 & 0.027827 & 0.046322 & -193593 \\
N3 & -0.148959 & -0.085711 & -0.074808 & -0.076189 \\
C4 & -0.061262 & -0.047189 & -0.038762 & -0.006593 & -0.133267 \\
C5 & 0.023640 & 0.074464 & 0.051850 & -0.009596 \\
\hline
\end{tabular}

1) The scheme of imidazolium radical as<smiles>[R]c1c(C)c([R])n([R9])c1C</smiles> 


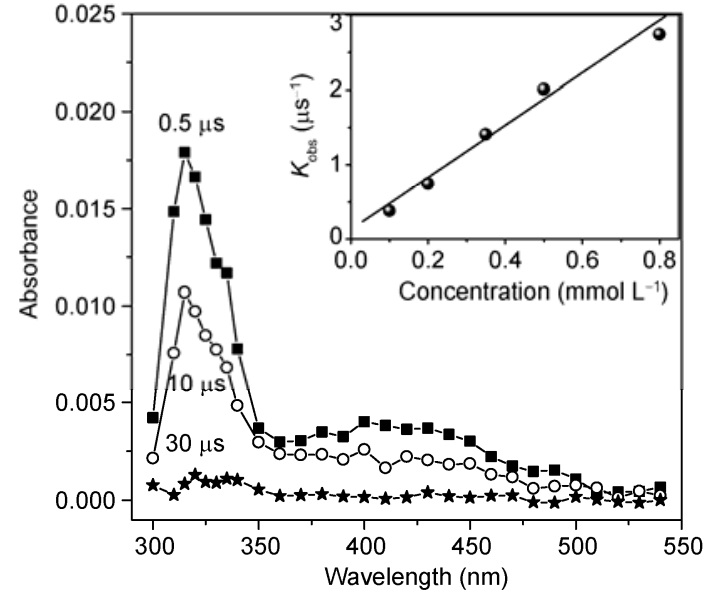

Figure 2 Transient absorption spectra of radicals produced by reaction of - $\mathrm{OH}$ with $0.1 \mathrm{mmol} \mathrm{L}^{-1} \mathrm{BMIBF}_{4}$ in $\mathrm{N}_{2} \mathrm{O}$-saturated aqueous solutions at $\mathrm{pH}$ 7.1, buffered with $2 \mathrm{mmol} \mathrm{L}^{-1}$ phosphate. Inset: Decay rates of the radicals produced by reaction of ${ }^{\circ} \mathrm{OH}$ with $\mathrm{BMIBF}_{4}$ at $320 \mathrm{~nm}$ plotted as a function of $\mathrm{BMIBF}_{4}$ concentration.

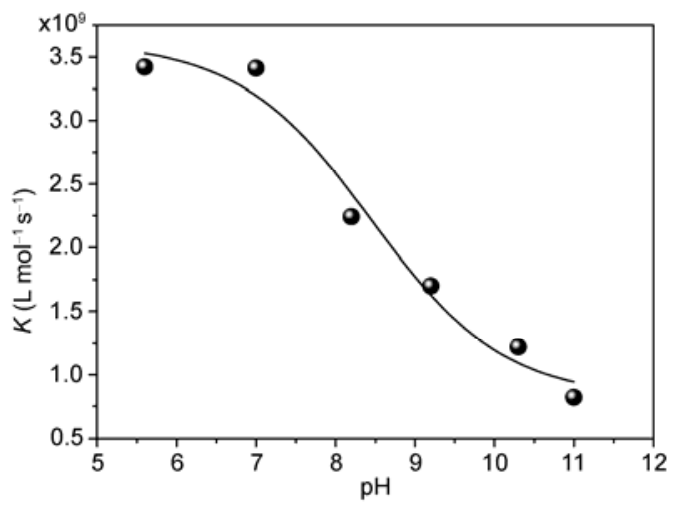

Figure 3 Growth rate constants of ${ }^{\circ} \mathrm{OH}$ reacting with $\mathrm{BMIBF}_{4}$ at $320 \mathrm{~nm}$ as a function of $\mathrm{pH}$.

\subsection{Reactions with $\mathrm{SO}_{4}{ }^{-}$}

The pulse radiolysis of $\mathrm{N}_{2}$-saturated aqueous solutions containing $0.5 \mathrm{mmol} \mathrm{L}^{-1}$ imidazolium-based ionic liquid, 50 mmol L ${ }^{-1} \mathrm{~K}_{2} \mathrm{~S}_{2} \mathrm{O}_{8}$, and $1.0 \mathrm{~mol} \mathrm{~L}^{-1} t$ - $\mathrm{BuOH}$ gave a transient optical absorption spectra, as shown in Figure 4. The absorption peak which appeared after a short time at $460 \mathrm{~nm}$ was attributed to $\mathrm{SO}_{4}{ }^{--}$. $\mathrm{SO}_{4}{ }^{--}$is a strong oxidant and can completely oxidize imidazolium cations to $\mathrm{BMI}^{2+}$, as shown in eq. (10). However, another weaker peak appeared at around $320 \mathrm{~nm}$ after $2 \mu \mathrm{s}$. To test the attribution of the absorption band at around $320 \mathrm{~nm}$, the spectrum of 50 mmol L $\mathrm{L}^{-1} \quad \mathrm{~K}_{2} \mathrm{~S}_{2} \mathrm{O}_{8}$ without imidazolium salts was determined, and there was a very weak $\mathrm{SO}_{4}{ }^{-}$absorption at 320 $\mathrm{nm}$. The absorption peak at $320 \mathrm{~nm}$ was therefore mainly attributed to the cation radical $\mathrm{BMI}^{2+}$. However, the spectra of $\mathrm{BMI}^{+}$reacting with $\mathrm{SO}_{4}{ }^{-}$were quite different from that observed for the $\mathrm{OH}$ adduct $\mathrm{BMI}-\mathrm{OH}^{*+}$. The latter showed a typical maximum absorption band at $325 \mathrm{~nm}$ and another- broad band at around 390-460 $\mathrm{nm}$.

$$
\mathrm{SO}_{4}{ }^{--}+\mathrm{BMI}^{+} \longrightarrow \mathrm{BMI}^{2+}+\mathrm{SO}_{4}{ }^{2-}
$$

Using five $\mathrm{BMIBF}_{4}$ concentrations varying from 0.15 to $1.5 \mathrm{mmol} \mathrm{L}^{-1}$, the rate constant was calculated to be $1.2 \times 10^{9}$ $\mathrm{L} \mathrm{mol}{ }^{-1} \mathrm{~s}^{-1}$. Except in the case of $\mathrm{HOMIBF}_{4}$, the rate constants of other tested ionic liquids with $\mathrm{SO}_{4}{ }^{2-}$ were almost the same as those in Table 2. The value for $\mathrm{HOMIBF}_{4}$ was slightly lower, $2.8 \times 10^{8} \mathrm{~L} \mathrm{~mol}^{-1} \mathrm{~s}^{-1}$. This may be because of the hydroxyethyl substituent, which is an electron-withdrawing group, on the imidazolium ring.

\subsection{Pulse radiolysis of neat ionic liquids}

In general, pulse radiolysis of neat imidazolium-based ionic liquids $\mathrm{BMI}^{+} \mathrm{X}^{-}$initially produces solvated electrons $\left(\mathrm{e}_{\text {solv }}{ }^{-}\right)$ and other radical cations and anions such as $\mathrm{BMI}^{2+}, \mathrm{NTF}_{2}{ }^{\circ}$, $\mathrm{Br}_{2}{ }^{-}$, and $\mathrm{Cl}_{2}{ }^{--}$, as shown in eqs. (11)-(16). The solvated electrons, which had typical absorptions above $1100 \mathrm{~nm}$, reacted with $\mathrm{BMI}^{+}$very quickly to produce $\mathrm{BMI}$. The transient absorption spectra of imidazolium-based ionic liquids with different anions showed slight differences in the maximum absorption peaks. For $\mathrm{BMIPF}_{6}$ and $\mathrm{BMINTF}_{2}$, the peaks were very similar (Figure 5(a) and (b)), which indicated that these anions were inert. However, for $\mathrm{BMICl}$ and $\mathrm{BMIBr}$, the absorption peaks were about 340 and $360 \mathrm{~nm}$, respectively (Figure 5(c) and (d)). It is expected that similar to the case in aqueous solutions, halide atoms would be stabilized through the formation of complex radical anions (eqs. (13) and (14)). The radical anions $\mathrm{Cl}_{2}{ }^{-}$and $\mathrm{Br}_{2}{ }^{-}$had typical absorptions at around 340 and $360 \mathrm{~nm}$, respectively [23,24]. In ionic liquids, the stabilization effect should be even stronger as a result of the smaller energy of solvation of the anions and the greater stabilization by large radical anions. Michalski et al. [25] also showed that at ambient temperature and at $-196^{\circ} \mathrm{C}$, the radical anion $\mathrm{Br}_{2}{ }^{-}$was the major product upon radiolysis of neat ionic liquid BMIBr. The redox potentials of the dihalide anion radicals $\left(\mathrm{Br}_{2}{ }^{-}\right.$and $\left.\mathrm{Cl}_{2}{ }^{-}\right)$in aqueous solutions were 2.09 and $1.6 \mathrm{~V}$ for $E^{\circ}\left(\mathrm{Cl}_{2}{ }^{-} / 2 \mathrm{Cl}^{-}\right)$and $E^{\circ}\left(\mathrm{Br}_{2}{ }^{-} / 2 \mathrm{Br}^{-}\right)$, respectively [26]. It is therefore very likely that the use of ionic liquids, with different halide anions, as additives to organic solvents would result in the formation of oxidizing species analogous to those formed in non-aqueous environments.

$$
\begin{aligned}
& \mathrm{BMI}^{+} \mathrm{X}^{-} \longrightarrow \mathrm{BMI}^{\cdot}, \mathrm{BMI}^{\circ+}, \mathrm{X}^{\cdot}, \mathrm{e}_{\text {solv }}^{-} \\
& \mathrm{e}_{\text {solv }}^{-}+\mathrm{BMI}^{+} \longrightarrow \mathrm{BMI}^{\cdot} \\
& \mathrm{Cl}^{-}+\mathrm{Cl}^{-} \longrightarrow \mathrm{Cl}_{2}^{--} \\
& \mathrm{Br}^{-}+\mathrm{Br}^{-} \longrightarrow \mathrm{Br}_{2}^{--} \\
& \mathrm{PF}_{6}^{-} \longrightarrow \mathrm{PF}_{6}^{-}+\mathrm{e}^{-} \\
& \mathrm{NTF}_{2}^{-} \longrightarrow \mathrm{NTF}_{2}^{-}+\mathrm{e}^{-}
\end{aligned}
$$

\section{Conclusion}

The rate constants of various imidazolium-based cations 


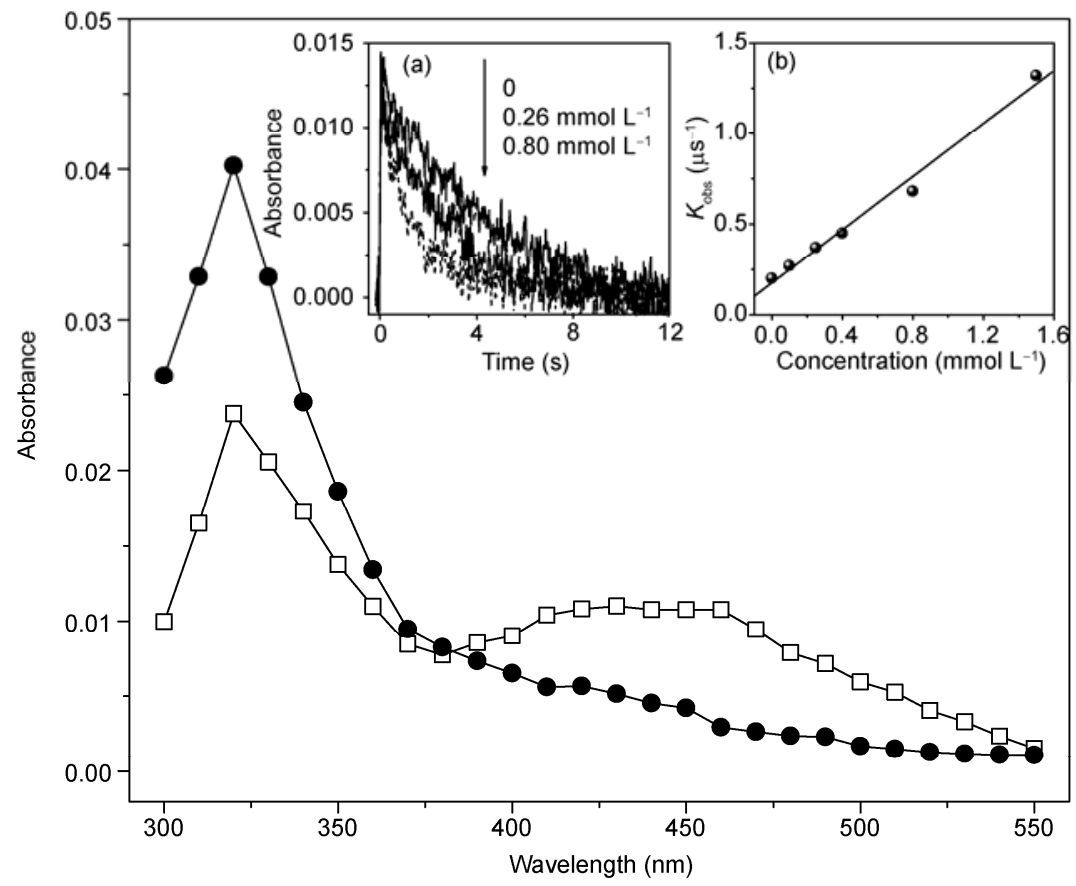

Figure 4 Transient absorption spectra of $\mathrm{BMIBF}_{4}$ produced by reaction of $\mathrm{BMI}^{+}$with $\mathrm{SO}_{4}{ }^{-}$radicals in $\mathrm{N}_{2}$-saturated aqueous solutions at $\mathrm{pH} 7.1$ containing $1.0 \mathrm{~mol} \mathrm{~L}^{-1}$ tert-butyl alcohols buffered with $2 \mathrm{mmol} \mathrm{L}^{-1}$ phosphate, recorded at () 0.2 and (•) $2 \mu$ s after the pulse. Inset: (a) Time profiles observed at 460 $\mathrm{nm}$ for $\mathrm{SO}_{4}{ }^{-}$and (b) decay rate of $\mathrm{SO}_{4}{ }^{-}$at $460 \mathrm{~nm}$ plotted as a function of $\mathrm{BMIBF}_{4}$ concentration.
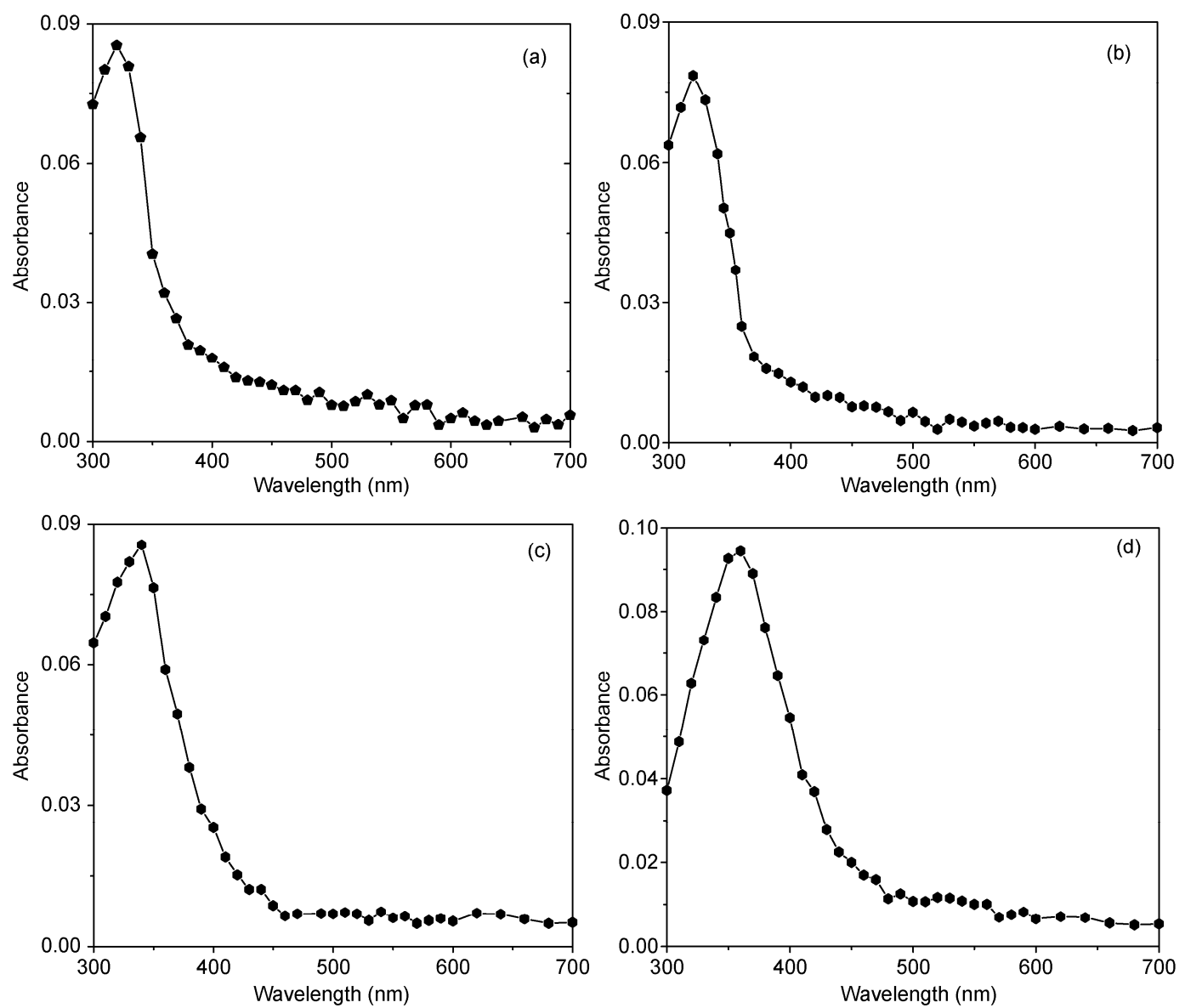

Figure 5 Transient absorption spectra measured $0.5 \mu$ s after the electron pulse radiolysis of neat ionic liquids under the same conditions: $\mathrm{N}_{2}$-saturated (a) $\mathrm{BMIPF}_{6}$; (b) $\mathrm{BMINTF}_{2}$; (c) BMICl; and (d) BMIBr. 
with hydrated electrons, hydroxyl radicals, and sulfate anion radicals were investigated using nanosecond pulse radiolysis techniques. The values were deduced to be of the order of magnitude $10^{9}-10^{10} \mathrm{~L} \mathrm{~mol}^{-1} \mathrm{~s}^{-1}$. Under the experimental conditions, it was found that the length of the alkyl chain on the imidazole ring and the anion type had hardly any influence on the reactions with hydroxyl radicals and sulfate anion radicals. However, when the imidazolium rings were substituted at the 2-position, the rate constants with hydrated electrons were a little lower. For example, for $\mathrm{BMMIBF}_{4}$ and $\mathrm{BMIBF}_{4}$, the values were $5.5 \times 10^{9}$ and $1.8 \times 10^{10} \mathrm{~L} \mathrm{~mol}^{-1} \mathrm{~s}^{-1}$, respectively. Gaussian calculations further confirmed that the electron cloud changed with the substituent on the imidazolium ring, and this influenced the reactivities of ionic liquids with various radicals.

This work was supported by the National Natural Science Foundation of China (20973192, 11079007). The authors also thank Mr. Tieming Yu and Shanliang Lu for their technical support for the radiolysis experiments.

1 Welton T. Room-temperature ionic liquids: Solvents for synthesis and catalysis. Chem Rev, 1999, 99: 2071-2083

2 Rogers R D, Seddon K R. Ionic Liquids As Green Solvents: Progress and Prospects. Washington DC: American Chemical Society, 2003. 856

3 Dupont J. On the solid, liquid and solution structural organization of imidazolium ionic liquids. J Braz Chem Soc, 2004, 15: 341-350

4 Earle M J, Seddon K R. Ionic liquids. Green solvents for the future. Pure Appl Chem, 2000, 7: 1391-1398

5 Wasserscheid P, Welton T. Ionic Liquids in Synthesis. Weinheim: Wiley-VCH, 2003

6 Shkrob I A, Chemerisov S D, Wishart J F. The initial stage of radiation damage in ionic liquids and ionic liquid-based extraction systems. J Phys Chem B, 2007, 111: 11786-11793

7 Harmon C D, Smith W H, Costa D A. Criticality calculations for plutonium metal at room temperature in ionic liquid solutions. Radiat Phys Chem, 2001, 60: 157-159

8 Grodkowski J, Neta P, Wishart J F. Pulse radiolysis study of the reaction of hydrogen atoms in the ionic liquid methyltributylammonium bis (trifluoromethylsulfonyl) imide. J Phys Chem A, 2003, 107: 9794-9799

9 Asano A, Yang J F, Kondoh T, et al. Molar absorption coefficient and radiolytic yield of solvated electrons in diethylmethyl(2-methoxy) ammonium bis(trifluoromethanesulfonyl)imide ionic liquid. Radiat
Phys Chem, 2008,77: 1244-1247

10 Grodkowski J, Neta P. Reaction kinetics in the ionic liquid methyltributylammonium-bis(trifluoromethylsulfonyl)imide, pulse radiolysis study of CF3 radical reactions. J Phys Chem A, 2002, 106: 5468-5473

11 Kondoh T, Asano A, Yang J F, et al. Pulse radiolysis study of ion-species effects on the solvated electron in alkylammonium ionic liquids. Radiat Phys Chem, 2009, 78: 1157-1160

12 Wishart J F, Neta P. Spectrum and reactivity of the solvated electron in the ionic liquid methyltributylammonium bis(trifluoromethylsulfonyl)imide. J Phys Chem B, 2003, 107: 7261-7267

13 Behar D, Gonzalez C, Neta P. Reaction kinetics in ionic liquids: Pulse radiolysis studies of 1-butyl-3-methylimidazolium salts. J Phys Chem A, 2001, 105: 7607-7614

14 Wishart J F, Lall-Ramnarine S I, Raju R, et al. Effects of functional group substitution on electron spectra and solvation dynamics in a family of ionic liquids. Radiat Phys Chem, 2005, 72: 99-104

15 Bonhôte P, Dias A P, Papageorgiou N, et al. Hydrophobic, highly conductive ambient-temperature molten salts. Inorg Chem, 1996, 35: 1168-1178

16 Zhang P, Yao S D, Li H X, et al. Pulse radiolysis study on several fluoroquinolones. Radiat Phys Chem, 2011, 80: 548-553

17 Buxton G V, Greenstock C L, Helman W P, et al. Critical-review of rate constants for reactions of hydrated electrons, hydrogen-atoms and hydroxyl radicals $\left({ }^{\bullet} \mathrm{OH} / \mathrm{O}^{\bullet-}\right.$ ) in aqueous-solution. J Phys Chem Ref Date, 1988, 17: 513-886

18 Rao P S, Simic M, Hayon E. Pulse-radiolysis study of imidazole and histidine in water. J Phys Chem, 1975, 79: 1260-1263

19 Takahashi K, Sato T, Katsumura Y, et al. Reactions of solvated electrons with imidazolium cations in ionic liquids. Radiat Phys Chem, 2008, 77: 1239-1243

20 Hayashi K, Nemoto Y, Akuto K, et al. Alkylated imidazolium salt electrolyte for lithium cells. J Power Source, 2005, 146: 689-692

21 Frisch M J, Trucks G W, Schlegel H B. Gaussian 03, Revision B.03. Pittsburgh PA: Gaussian Inc, 2003

22 Becke A D. Density-functional thermochemistry. 3. The role of exact exchange. J Chem Phys, 1993, 98: 5648-5652

23 Adams G E, Aldrich J E, Bisby R H, et al. Selective free-radical reactions with proteins and enzymes-reactions of inorganic radical anions with amino-acids. Radiat Res, 1972, 49: 278-289

24 Scaiano J C, Barra M, Krzywinski M, et al. Laser flash-photolysis determination of absolute rate constants for reactions of bromine atoms in solution. J Am Chem Soc, 1993, 115: 8340-8344

25 Michalski R, Sikora A, Adamus J, et al. Dihalide and pseudohalide radical anions as oxidizing agents in nonaqueous solvents. J Phys Chem A, 2010, 114: 861-866

26 Neta P, Huie E, Ross A B. Rate constants for reactions of inorganic radicals in aqueous solution. J Phys Chem Ref Data, 1988, 17: 1027-1284

Open Access This article is distributed under the terms of the Creative Commons Attribution License which permits any use, distribution, and reproduction in any medium, provided the original author(s) and source are credited. 